УДК 504.42(269.718):504.054

\title{
ОЦЕНКА ЗАГРЯЗНЕНИЯ БАРЕНЦЕВА МОРЯ ПЛАВАЮЩИМ МОРСКИМ МУСОРОМ ПО ДАННЫМ СУДОВЫХ НАБЛЮДЕНИЙ В 2019 Г.
}

\author{
Погожева Мария Петровна 1,2 , \\ pogojeva_maria@mail.ru
}

\section{Якушев Евгений Владимирович1,3, evgeniy.yakushev@niva.no}

Терский Петр Николаевич², peter.tersky@gmail.com

\section{Глазов Дмитрий Михайлович4, dglazov@yandex.ru}

\author{
Аляутдинов Вадим Алиевич2, \\ vada.90@mail.ru
}
Коршенко Александр Николаевич² korshenk058@mail.ru

Ханке Георг ${ }^{5}$, georg.hanke@ec.europa.eu

\section{Семилетов Игорь Петрович 6 , igorsm@poi.dvo.ru}

1 Институт океанологии им. П.П. Ширшова Российской академии наук, Россия, 117997, г. Москва, Нахимовский пр., 36.

2 Государственный океанографический институт им. Н.Н. Зубова, Росгидромет, Россия, 119034, г. Москва, Кропоткинский пер., 6.

3 Норвежский институт водных исследований, Норвегия, 0349, г. Осло, Гаустадаллеен, 21.

4 Институт проблем экологии и эволюции им. А.Н. Северцова Российской академии наук, Россия, 119071, г. Москва, Ленинский пр., 33.

5 Объединенный научный центр, Италия, 21027, г. Испра, Виа Е.Ферми, 2749.

6 Тихоокеанский океанологический институт им. В.И. Ильичева Дальневосточного отделения Российской академии наук, Россия, 60041, г. Владивосток, ул. Балтийская, 43.

\begin{abstract}
Актуальность исследования обусловлена постоянно увеличивающимся накоплением пластикового мусора в морской среде, что вызывает серьезную обеспокоенность как у научного сообщества, так и у широкой общественности. Мусор оказывает все большее воздействие на живые организмы, качество морских вод и экосистемы в иелом, часто затрагивая условия жизни и здоровья в том числе и человека. Учитывая глобальную циркуляцию водных масс, природные условия, а также постоянно возрастающую нагрузку, связанную с потеплением климата, Арктика потенциально может служить местом накопления пластиковых отходов.

Целью данной работы является оценка уровня загрязнения плавающим мусором Баренцева моря, включающая в себя получение новых данных об особенностях аккумуляции мусора на поверхности воды и обсуждение потенциальных источников его поступления и переноса.

объект: плавающие на поверхности моря частицы различного происхождения (морской мусор).

Методы. В ходе экспедиции параллельно с визуальными наблюдениями было протестировано и применено мобильное приложение Floating Litter Monitoring (FLM), которое может использоваться для упрощения и стандартизации сбора данных о плавающем мусоре.

Результаты. Было обнаружено, что средняя плотность мусора на всех разрезах соответствует примерно 3,5 частии/км². На некоторых участках маршрута судна были отмечены множественные значительные зоны скопления плавающего морского мусора, ранее не упоминавшиеся в литературе. Сделаны предположения о возможных причинах скопления плавающего мусора в восточной части Баренцева моря, а также приводятся рекомендации по сокращению поступления количества мусора в морскую среду и проведению регулярных мониторинговых исследований с использованием стандартизированных методик.
\end{abstract}

Ключевые слова:

Загрязнение морских вод, морской мусор, Арктика, Баренцево море, мониторинг.

\section{Введение}

В настоящее время загрязнение морским мусором, особенно состоящим из пластика, является одной из наиболее актуальных проблем антропогенного воздействия на морскую среду в глобальном масштабе [1]. По текущим оценкам количество пластика, поступающего с суши в морскую среду ежегодно, варьируется от 4,5 до 12,7 млн т, а еще 1,75 млн т происходит из так называемых морских источников, таких как рыболовство, аквакультура (рыбоводство) и судоходство [2].

Макропластик (бутылки, пакеты и пр.) и микропластик (фрагменты и синтетические волокна размером менее 5 мм) [3] обнаруживаются во всех природных средах, включая моря. Наиболее распространенные формы пластика - полипропилен (бутылки) и по-

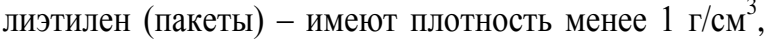
поэтому они всплывают на поверхность воды, в то 
время как другие формы, такие как нейлон (рыболовные сети) и ПВХ (трубы), имеют большую плотность и могут тонуть и накапливаться в донных отложениях Глубоководные условия с более холодными температурами и недостатком ультрафиолета особенно благоприятны для сохранения пластика. В таких условиях пластик может оставаться в донных отложениях в течение геологических масштабов времени [4].

В Мировом океане морской мусор переносится течениями и из-за особенностей глобальной циркуляции скапливается в центрах пяти антициклонических круговоротов, расположенных в тропических зонах, при этом значительное количество пластика атлантического происхождения переносится в Арктику. Результаты моделирования предсказывают формирование зоны накопления морского мусора в Баренцевом море [5]. Этот район Северного Ледовитого океана играет ключевую роль в формировании глубинных арктических вод в процессе охлаждения [6], большая часть атлантических вод достигает восточной части Баренцева моря [7]. Таким образом, плавающий морской мусор, поступающий с береговых источников густонаселенных районов Северной Атлантики, может вовлекаться в глобальную систему термохалинной циркуляции и в конечном счете переноситься с теплыми поверхностными водами северной части океана к высоким арктическим широтам. Это потенциально приводит к его накоплению в Гренландском и Баренцевом морях, где острова, архипелаги и стабильный ледовый покров служат препятствием для его дальнейшего распространения в Северном Ледовитом океане. Дополнительным источником поступления морского мусора в регион являются арктические реки [8]. В настоящий момент знания о путях переноса и трансформации микропластика между различными объектами окружающей среды (например, поверхностью воды, водной толщью, донными осадками и биотой) весьма ограничены, что не позволяет достоверно выполнять оценки экологических рисков для этих объектов. Таким образом, наряду с пятью глобальными районами накопления мусора в тропических круговоротах может формироваться шестой - в Арктических водах, в районе Баренцева моря [9]. Недавний анализ четырех ледяных кернов, собранных за Северным полярным кругом, показал высокое содержание микропластика в морском льду [10], что также может свидетельствовать об активном поступлении морского мусора в полярные широты.

Целью данной работы является оценка уровня загрязнения плавающим мусором Баренцева моря, включающая в себя получение новых данных об особенностях аккумуляции мусора на поверхности воды и обсуждение потенциальных источников его поступления и переноса. Кроме того, в работе сравниваются два метода определения плавающего мусора: с использованием планшета/смартфона и визуальный.

\section{Материалы и методы}

С 15 мая по 14 июня 2019 г. состоялась комплексная научно-исследовательская экспедиция на научноэкспедиционном судне «Михаил Сомов» в рамках крупного национального проекта «ТРАНСАРКТИКА2019, II ЭТАП». Маршрут экспедиции проходил из г. Архангельска через Белое море вдоль архипелага Новая Земля к архипелагу Земля Франца-Иосифа и обратно до г. Архангельска, покрывая в основном акваторию восточной части Баренцева моря. На борту судна по ходу экспедиции проводилось обследование загрязнения акватории моря плавающим морским мусором. Наблюдения выполнялись по ходу движения судна двумя разными способами специалистами Государственного океанографического института им. Н.Н. Зубова (ГОИН), Института проблем экологии и эволюции им. А.Н. Северцова Российской академии наук (ИПЭЭ РАН) и ФГБУ Северное «УГМС».

Для первого способа была выбрана методика института Joint Research Center (Объединенный научный центр, г. Испра, Италия) [11], которая была впервые использована в северных морях (далее «Метод 1»). При помощи мобильного приложения Floating Litter Monitoring (FLM), установленного на планшет на базе Android, фиксировалось наличие крупных частиц морского мусора на поверхности моря. Наблюдения проводились с палубы судна во время движения. Полоса учета морского мусора варьировала в зависимости от метода и условий наблюдения. Исходя из высоты наблюдателя над урезом воды и условий наблюдения, выбиралась ширина полосы учета (обычно около 15-30 м), в которой наблюдатель гарантированно различает объекты более 2,5 см согласно методике [3]. Приложение позволяет записывать трек учета с привязкой каждого объекта к GPS координатам и идентифицировать объекты морского мусора по установленным общепринятым категориям. При встрече больших скоплений мусора, фактах подтверждения источников поступления мусора или взаимодействия его с морской фауной производилась фотофиксация. Все встреченные объекты антропогенного мусора дополнительно отмечались в полевом дневнике, в который также записывались погодные условия, волнение, ледовая обстановка, видимость и прочая сопровождающая информация.

В качестве второго способа применялся простой визуальный метод учета плавающего мусора (далее «Метод 2»). Наблюдения проводились по обоим бортам судна при благоприятных погодных и световых условиях круглосуточно семью сменными наблюдателями (вахты по 2 наблюдателя по 4 часа) с пеленгаторной площадки, расположенной над ходовым мостиком. Высота площадки над уровнем моря 17,5 м. При сильном ветре или во время осадков наблюдения проводились с ходового мостика. В темное время суток и при плохих погодных условиях: туман, сильный снег, дождь, волнение моря более 6 по шкале Бофорта, наблюдения не проводились. Все встречаемые частицы мусора фиксировались в бумажном протоколе с привязкой каждого объекта к GPS координатам. Записывались погодные условия, волнение, ледовая обстановка, видимость и прочая сопровождающая информация. Наблюдения включали идентификацию категорий мусора по составу согласно методике [3]. 
Одной из задач этих исследований было тестирование новой европейской методики по мониторингу плавающего мусора с помощью приложения FLM в арктических водах. Приложение позволяет в автоматическом режиме записывать координаты встреченных объектов мониторинга и сопутствующие метаданные, не отвлекаясь на другое оборудование и записи в блокноте. Перечень морского мусора и классификация его по категориям, использующаяся в приложении, соответствует последним мировым стандартам [3], что способствует сбору унифицированных данных. Данные записываются в формате csv, который при необходимости может открываться стандартной программой Microsoft Office Excel для последующей обработки информации. В то же время был отмечен и ряд сложностей, учет которых может позволить их избежать при последующих исследованиях. Например, для достоверного отображения полученных результатов следует обращать особое внимание на выбор в приложении ширины учетной трансекты, так как от этого напрямую зависит расчет плотности мусора на единицу площади. При дальнейшей экстраполяции результатов это может стать серьезной ошибкой. Наблюдался также ряд технических трудностей при передаче и обработке данных. Опыт этих работ поможет учитывать в дальнейшем возможные сложности. В целом на протяжении экспедиции приложение FLM работало без сбоев, показало себя легким и удобным в использовании при благоприятных погодных условиях.

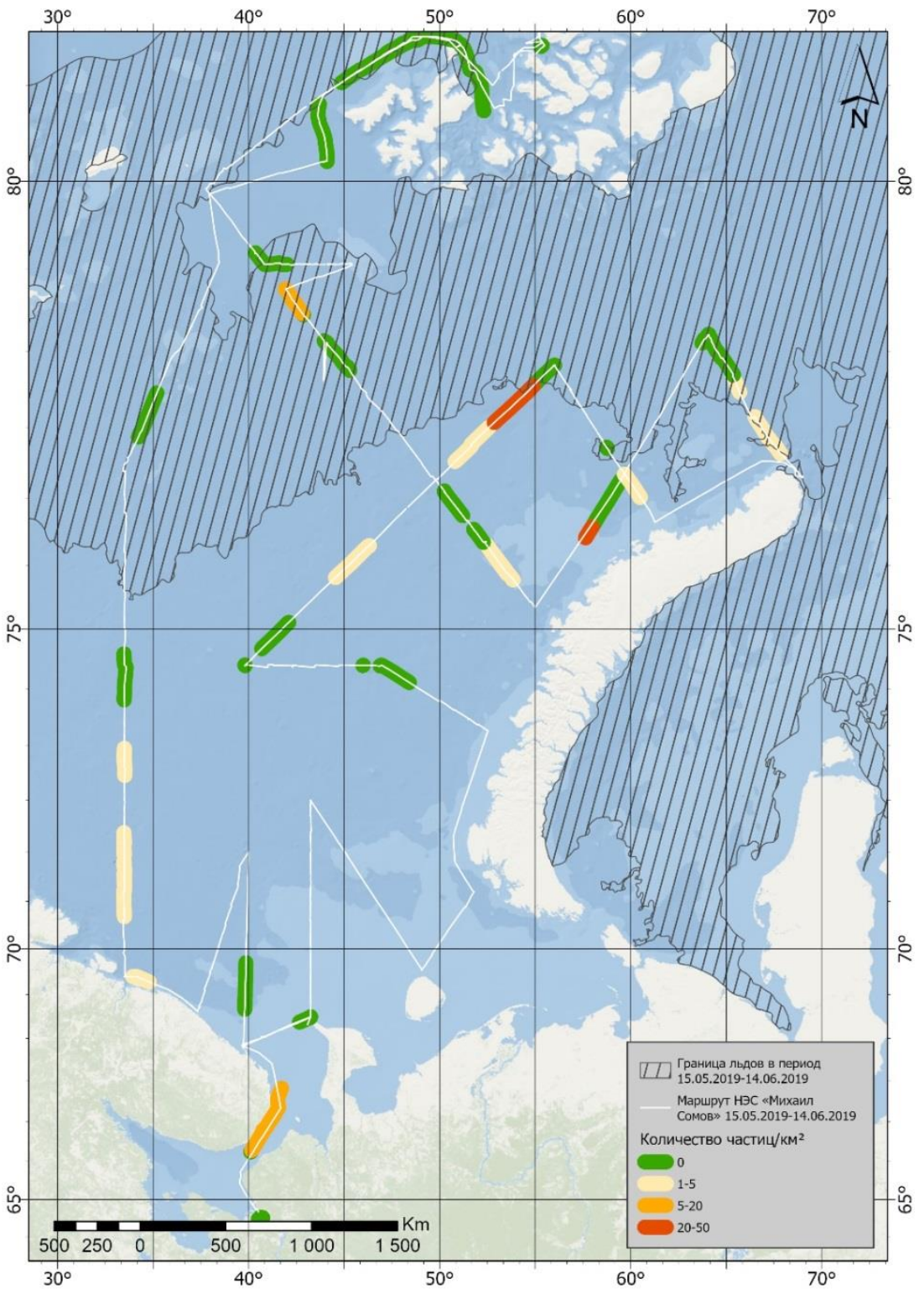

Рис. 1. Загрязненность морским мусором в восточной части Баренщева моря на разрезах экспедиции НЭС «Михаил Сомов» 15.05-14.06.2019 2., зарегистрированных при помощи мобильного приложения FLM (количество частии $\left./ \mathrm{km}^{2}\right)$. Средняя граница ледового покрова представлена согласно оперативным данным по ледовой обстановке [12]

Fig. 1. Density of FMML in the eastern part of the Barents Sea during expedition on $R / V$ «Mikhail Somov» 15.05-14.06.2019 on the transects registered with FLM mobile application (items $/ \mathrm{km}^{2}$ ). Relevant ice cover [12] 


\section{Результаты}

Всего в экспедиции были проведены наблюдения вдоль трека судна длиной 5824 км методом 1 и длиной 8509 км методом 2. Плавающий морской мусор встречался в течение всей экспедиции. Плотность плавающего мусора на разрезах сильно варьировалась, наблюдались как обширные участки без мусора, так и значительные скопления мусора разного размера. Результаты выполненных исследований по оценке распределения плавающего морского мусора на акватории Баренцева моря представлены в графическом виде (рис. 1). Линиями разного цвета отображены разрезы, на которых проводился мониторинг, цветом показаны градации плотности мусора на разрезах.
Полученные данные показали, что большая часть разрезов была свободна от мусора, на 9 разрезах концентрация мусора была оценена в интервале от 1 до 5 частиц/км ${ }^{2}$, на 37 - от 5 до 20 и на 20 разрезах - от 20 до 50 частиц/км². Наиболее значительные концентрации были отмечены в горле Белого моря и в открытых водах между северной частью арх. Новая Земля и Землей Франца-Иосифа. Средняя концентрация по собранным в приложении данным составила $3,5 \pm 8,8$ частиц/км².

Во время выполнения мониторинга Методом 2 большая часть мусора наблюдалась в восточной части маршрута исследований вдоль арх. Новая Земля (рис. 2).

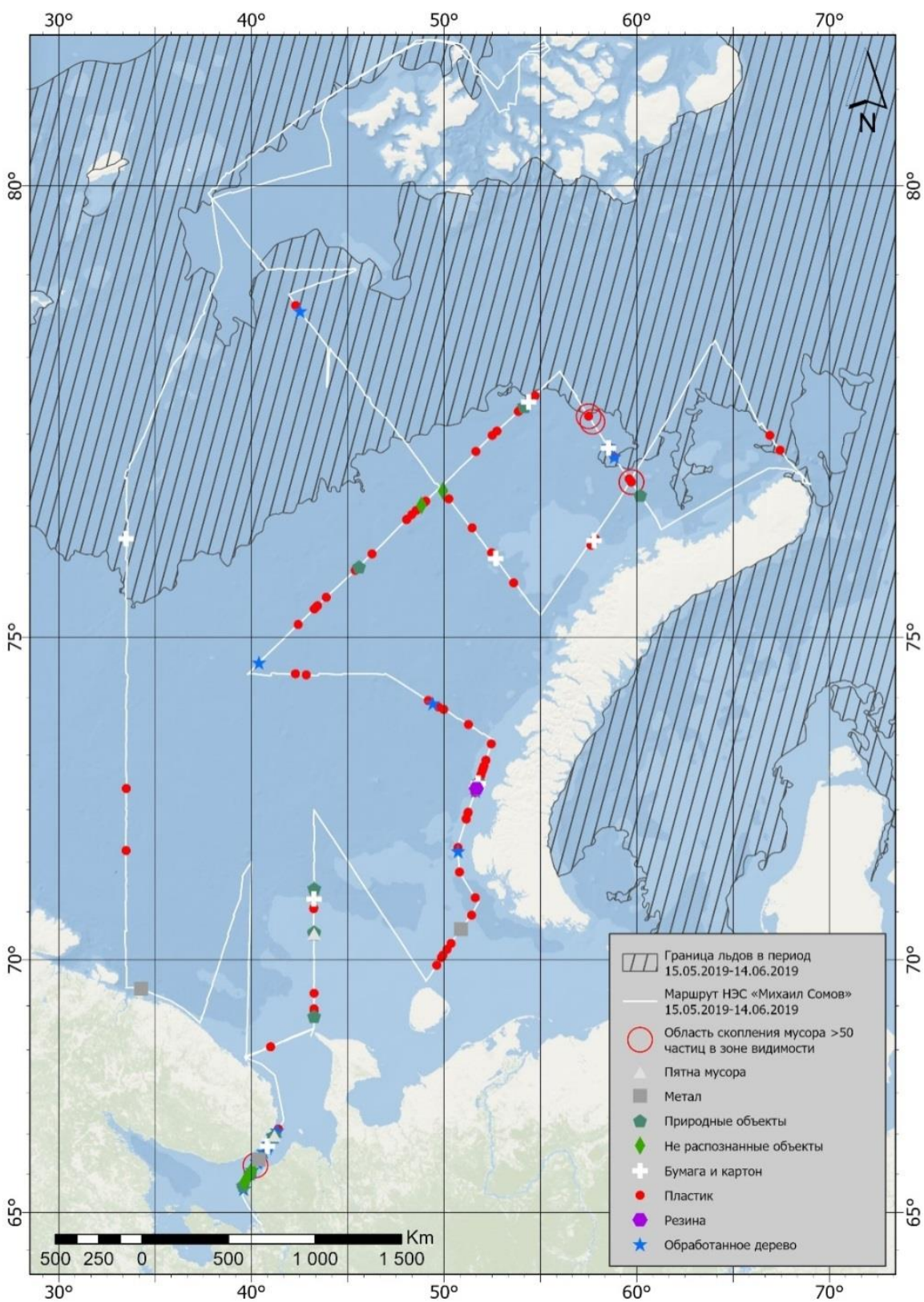

Pис. 2. Скопления мусора и категории мусора по составу, зарегистрированные в ходе постоянных наблюдений по ходу движения судна во время простых визуальных наблюдений. Средняя граница ледового покрова представлена согласно оперативным данным по ледовой обстановке [12]

Fig. 2. Categories of FMML by composition and accumulation zones recorded during simple visual observations along the vessel route. Relevant ice cover [12] 
При встрече большого количества мусора отмечались зоны скопления без идентификации объектов (large litter accumulations). По отзывам наблюдателей, через подобные мусорные «пятна» судно могло идти несколько минут. Были зафиксированы мусорные скопления с высокой плотностью шириной до 250 м и длиной до 7 км. По визуальным оценкам в одном таком «пятне» могло содержаться более 100 частиц с расстоянием между частицами от нескольких см до сотен метров. Такие значительные области накопления мусора были отмечены в горле Белого моря и у северной части Новой Земли, что в целом совпадает с данными, полученными при помощи приложения.
Анализ состава встреченного мусора во время визуальных наблюдений показал, что большую часть, как и ожидалось, составляет пластик (65 и $67 \%$, Meтодом 1 и Методом 2, соответственно), далее по убыванию следуют обработанное дерево (12 и $2 \%$ ), бумага и картон $(6,4 \%)$, не распознанные объекты и пятна мусора (по 3 \%), метал (алюминиевые банки, 2 , $1 \%)$ и резина $(2,1 \%)$; во время работы Методом 2 выделялся мусор, относящийся к рыболовству - веревки, буи, обрывки сетей - $11 \%$ (рис. 3). Природные объекты (деревья, ветки, листья и пр.) составили 21 и $9 \%$ соответственно и не учитывались как мусор обоими методами (nonlitter).

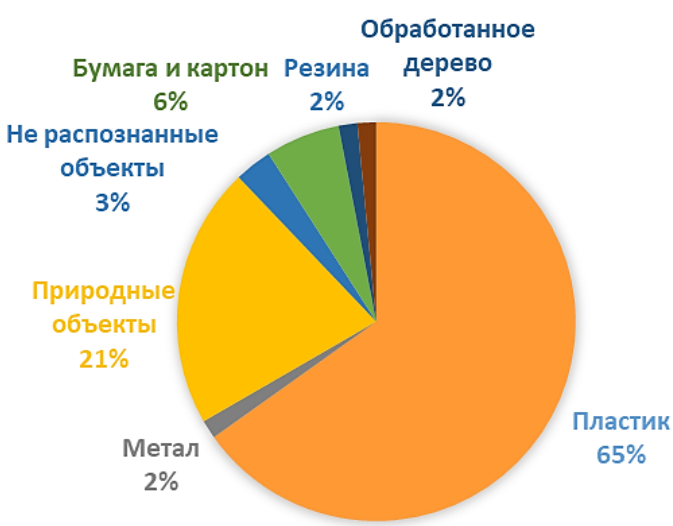

Метод 1

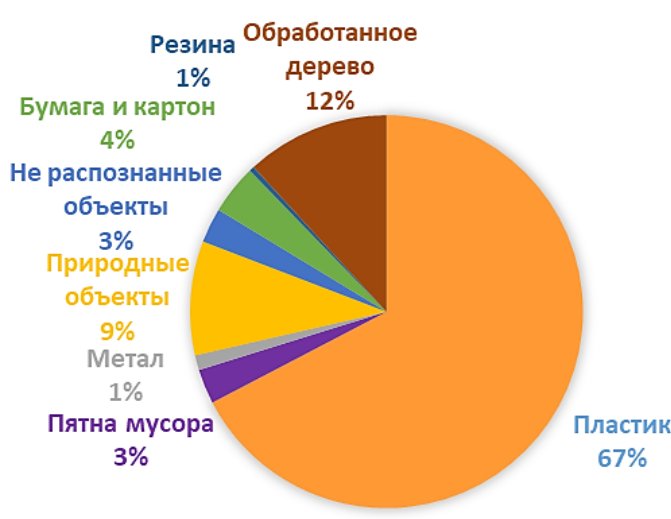

Метод 2

Рис. 3. Процентное соотношение по количеству встреченного морского мусора различного состава от суммарного, оиененное по Методу 1 и Методу 2

Fig. 3. Percentage ratio of the amount of encountered marine debris by composition from the total amount, estimated by Method 1 and Method 2

\section{Обсуждение}

Сравнение полученных результатов с подобными исследованиями в других морях представляется затруднительным из-за разности использованных методов и единиц измерения. Для европейских морей в последнее время принято оценивать плотность плавающего встреченного морского мусора на квадратный километр (количество частиц/км ${ }^{2}$ ). Данные недавних исследований в северо-западной части Черного моря показывают среднюю плотность на исследованных разрезах 30,9 частиц/км² [13] (таблица), в то же время по данным проекта ЭМБЛАС-II средняя плотность морского мусора в различных регионах Черного моря оценивается в 90,5 частиц/км² [14].

В различных районах Средиземного моря была зарегистрирована средняя плотность от 10,9 [16] до 232 частиц/км² [16]. По данным из относительно мало загрязненных районов, например, в Южном океане, концентрация морского мусора соответствуют 0,003-6,0 частиц/км².

Как указано выше, на основании модельных расчетов было установлено, что плавающий и подповерхностный пластик должен накапливаться в центрах океанских тропических круговоротов и в Баренцевом море [5]. Выполненные в тропических круговоротах полевые исследования подтверждают, что количество плавающего мусора там значительно больше, чем в других районах и достигает максимальных значений по одним оценкам в 15222 частиц/км ${ }^{2}$ [27], а по другим в 969777 частиц/км ${ }^{2}$ [28]. Полученные нами оценки плотности плавающего морского мусора в Баренцевом море (в среднем от 1 до 50 частиц/км²), а также обнаруженные нами зоны скопления, где точную плотность подсчитать не удалось, свидетельствует о том, что загрязнение Баренцева моря вполне может быть сопоставимо с существующим на сегодняшний день загрязнением по крайней мере в южных морях Европы, а возможно, и в тропических круговоротах. Однако необходимы дополнительные исследования с применением стандартизованных методов, так как существующие в настоящее время оценки, полученные разными методами (таблица), сравнивать не вполне корректно.

За многовековую историю использования человеком океана и его ресурсов сложилось представление о его безграничных возможностях, в том числе и с точки зрения захоронения различных видов отходов. До сих пор повсеместно распространен выброс за борт бытовых отходов с судов, несмотря на принятые многочисленные международные и региональные законодательства в этой сфере. Проблема поступления пластикового мусора в арктические воды является новой и малоизученной, хотя становится все более 
актуальной по мере его накопления в водах Мирового океана. Уже сейчас морской мусор представляет серьезную угрозу для морских организмов и их местообитаний. К этому можно добавить этические и экономические факторы в районах, где скопления морского мусора наносят существенный урон туристической индустрии.

Таблица. Концентрация плавающего морского мусора (единии/км ${ }^{2}$ в в различных районах Мирового океана

Table. FMML densities (items $/ \mathrm{km}^{2}$ ) in different areas of the Ocean

\begin{tabular}{|c|c|c|}
\hline \multirow[t]{2}{*}{ Район/Region } & $\begin{array}{c}\text { Средняя } \\
\text { концентрация } \\
\text { Mean } \\
\text { concentration } \\
\end{array}$ & $\begin{array}{c}\text { Максимальная } \\
\text { концентрация } \\
\text { Maximum } \\
\text { concentration }\end{array}$ \\
\hline & \multicolumn{2}{|c|}{ единиц $/ \mathrm{\kappa m}^{2}\left(\right.$ items $\left./ \mathrm{km}^{2}\right)$} \\
\hline $\begin{array}{l}\text { Черное море (Керченский пролив) } \\
\text { Black Sea (Kerch Strait) [15] }\end{array}$ & 66 & - \\
\hline $\begin{array}{l}\text { Черное море } \\
\text { (Северо-западная часть) } \\
\text { Northeastern Black Sea [13] }\end{array}$ & 30,9 & - \\
\hline $\begin{array}{l}\text { Черное море (проект ЭМБЛАС-II) } \\
\text { Black Sea (Project EMBLAS-II) [14] }\end{array}$ & 90,5 & 800 \\
\hline $\begin{array}{l}\text { Средиземное море } \\
\text { Mediterranean Sea [16] }\end{array}$ & $10,9-52$ & 194,6 \\
\hline $\begin{array}{l}\text { Средиземное море } \\
\text { Mediterranean Sea [17] }\end{array}$ & 232 & 1593 \\
\hline Северное море/North Sea [18] & 2 & $1-6$ \\
\hline Северное море/North Sea [19] & $25-38$ & - \\
\hline Чили/Chile [20] & $10-50$ & 250 \\
\hline $\begin{array}{l}\text { Южно-Китайское море } \\
\text { South China Sea [21] }\end{array}$ & 4,9 & 16,9 \\
\hline $\begin{array}{l}\text { Северная часть Тихого океана } \\
\text { North Pacific [22] }\end{array}$ & 459 & - \\
\hline $\begin{array}{l}\text { Малаккский пролив } \\
\text { Strait of Malacca [23] }\end{array}$ & 579 & - \\
\hline $\begin{array}{l}\text { Бенгальский залив } \\
\text { Bay of Bengal [23] } \\
\end{array}$ & 8,8 & - \\
\hline $\begin{array}{l}\text { Южный океан } \\
\text { Southern Ocean [24] }\end{array}$ & $0,0032-6$ & - \\
\hline $\begin{array}{l}\text { Британская Колумбия } \\
\text { British Columbia [25] } \\
\end{array}$ & 1,48 & 2,3 \\
\hline $\begin{array}{l}\text { Западная часть Гавайских островов } \\
\text { West of Hawaii [26] }\end{array}$ & 0,5 & - \\
\hline $\begin{array}{l}\text { Северотихоокеанский круговорот } \\
\text { North Pacific Gyre [27] }\end{array}$ & - & 15222 \\
\hline $\begin{array}{l}\text { Северотихоокеанский круговорот } \\
\text { North Pacific Gyre [28] }\end{array}$ & 334271 & 969777 \\
\hline $\begin{array}{l}\text { Баренцево море (данная работа) } \\
\text { Barents Sea (this work) }\end{array}$ & 3,5 & - \\
\hline
\end{tabular}

В данном исследовании представлены первые данные о загрязнении восточной части Баренцева моря плавающим морским мусором. Было обнаружено, что средняя плотность мусора на всех разрезах соответствует 3,5 частиц/км². На некоторых участках маршрута судна были отмечены множественные значительные зоны скопления плавающего мусора, ранее не упоминавшиеся в научной литературе.

В результате проведенной экспедиции было протестировано приложение FLM для мониторинга плавающего морского мусора. Апробация в полевых условиях доказала удобство его использования для такого вида работ. Данное приложение может быть рекомендовано для последующих попутных наблюдений за плавающим морским мусором.
Сравнивая две методики, можно отметить, что второй вид мониторинга - с помощью бумажных протоколов - был более трудозатратным, менее технологичным, но в то же время и более надежным. Этот метод не позволил произвести сравнения по плотности мусора с предыдущим методом, а также с другими подобными исследованиями в других районах по причине отсутствия данных о длине и ширине треков, однако географический охват оказался намного шире, благодаря постоянным наблюдениям.

Несмотря на то, что Баренцево море представляется малонаселенным с практически отсутствующей промышленной и производственной деятельностью, наличие активного рыболовного промысла, добыча полезных ископаемых и, соответственно, активное судоходство создает существенную нагрузку на его экосистему, накладываясь на привнос морского мусора с морскими течениями из других районов Мирового океана [5]. В связи с потеплением климата в последние годы антропогенная нагрузка на экосистему Баренцева моря заметно увеличивается. Страны Арктического Союза формируют арктические войска и создают инфраструктуру для их обустройства, модернизируют вооружения в «полярном варианте», ускоренно строят новые корабли ледового класса, аэродромы и др. Получили заметное развитие и мирные виды морехозяйственной деятельности в бассейне Баренцева моря. Прежде всего, это развитие торгового флота, который использует незамерзающий порт Мурманск для транспортировки кузбасского угля, минеральных удобрений и многих других товаров на экспорт. Планируется дальнейшее увеличение объёмов перевалки грузов в этом порту, планируются и строятся перегрузочные терминалы, соответствующая сухопутная транспортная система. В Мурманске находится база атомных ледоколов, которые уже используются для проводки российских и зарубежных судов по Северному морскому пути в восточные районы российской Арктики, где осуществляется модернизация и строительство нескольких портов, и далее - до Берингова пролива [29].

Относительно высокое содержание плавающего мусора в восточной части Баренцева моря может быть связано с несколькими причинами. Во-первых, это может быть перенос из загрязненных районов Атлантики течениями, что подтверждается и другими исследованиями $[8,9]$. Во-вторых, значительным источником может служить сброс отходов с судов. Согласно Правилу 3 Приложения 5 Конвенции МАРПОЛ 73/78 [30], вне особых районов, к которым относится Баренцево море, разрешается сброс бытовых отходов в море за пределами 25-мильной зоны. В то же время Северный Морской Путь (СМП) имеет особые правила по обращению с отходами. Состав встреченного в данном исследовании морского мусора, представляющий в основном смесь бытовых отходов, позволяет предположить, что обширные скопления мусора в восточной части Баренцева моря у берегов Новой Земли могут быть связаны именно с законодательно разрешенным сбросом мусора в море перед входом в СМП, где это сделать, не нарушая правила, уже невозможно. 


\section{Заключение}

В настоящее время наблюдается негативная тенденция накопления морского мусора в водах Мирового океана в целом и в отдельных его районах. Баренцево море потенциально может служить местом активного его накопления подобно другим пяти глобальным океаническим круговоротам [9]. Выполненные исследования подтвердили предположения о скоплениях плавающего морского мусора в восточной части Баренцева моря. По предварительным оценкам на некоторых отрезках пути экспедиции плотность морского мусора была сопоставима со средними значениями в существенно более загрязненных южных морях Европы. Для уточнения фактических значений плотности и подтверждения полученных предварительных результатов рекомендуется проведение подобных исследований повторно с детальным следованием общепринятым методикам для возможности достоверного сравнения результатов [3].

Чтобы уменьшить объемы поступления пластиковых отходов в Мировой океан потребуется принятие целого ряда законодательных и практических мер по сокращению производства изделий из пластика, повторного использования и утилизации такого вида отходов, что нуждается в более подробных качественных и количественных исследованиях [31]. Регулярные мониторинговые исследования могли бы помочь в определении основных источников поступления мусора, распространения и влияния его на морские организмы, спланировать необходимые действия по предотвращению дальнейшего загрязнения аква-

\section{СПИСОК ЛИТЕРАТУРЫ}

1. Kershaw P.J. Marine plastic debris and microplastics global lessons and research to inspire action and guide policy change. Nairobi: UNEP, 2016. - 192 p.

2. Plastic waste inputs from land into the ocean / J.R. Jambeck, R. Geyer, C. Wilcox, T.R Siegler., M. Perryman, A. Andrady, R. Narayan, K.L. Law // Science. American Association for the Advancement of Science. - 2015. - V. 347. - № 6223. - P. 768-771.

3. Guidance on Monitoring of Marine Litter in European Seas / F. Galgani, G. Hanke, S. Werner, L. Oosterbaan, P. Nilsson, D. Fleet, S. Kinsey, J. van Franeker, T. Vlachogianni, M. Scoullos, J. Mira Veiga, A. Palatinus, M. Matiddi, T. Maes, S. Korpinen, A. Budziak, H. Leslie, J. Gago, G. Liebez // European Commission, Joint Research Centre. MSFD Technical Subgroup on Marine Litter (TG ML). - 2013. - № EUR 26113. - P. 1-126.

4. Ross N.L. The «plasticene» epoch? // Elements. Mineralogical Society of America. - 2018. - V. 14. - № 5. - P. 291-292.

5. Van Sebille E., England M.H., Froyland G. Origin, dynamics and evolution of ocean garbage patches from observed surface drifters // Environmental Research Letters. Institute of Physics Publishing. 2012. - V. 7. - № 4. - P. 1-6.

6. On the driving processes of the Atlantic meridional overturning circulation / T. Kuhlbrodt, A. Griesel, M. Montoya, A. Levermann, M. Hofmann, S. Rahmstorf // Reviews of Geophysics. - 2007. V. 45. - № 2. - P. 2001-2002.

7. Rudels B. Arctic ocean circulation // Encyclopedia of Ocean Sciences. - 2019. - C. 262-277

8. Studies of microplastic distribution in subsurface waters of the Arctic Seas in the 73 cruise of RV «Akademik Mstislav Keldysh», September-October 2018 / E. Yakushev, S. Pakhomova, A.L. Lusher, A. Mazur, A. Grinko, T. Dautova, D. Kosmach, A. Berezina // Geology of seas and oceans: Proc. of XXIII торий морским мусором. Подобные исследования должны выполняться по единым унифицированным методикам, таким как методики AMAP (Arctic Monitoring and Assessment Programme), OSPAR (Oslo and Paris Conventions for the Protection of the Marine Environment of the North-East Atlantic), MSFD (Marine Strategy Framework Directive) для возможности сравнения полученных результатов и быть одной из частей комплексного мониторинга морского мусора, включающего также мониторинг берегового мусора и мусора, поступающего в моря с водами рек.

Исследования были организованы в рамках комплексной научно-исследовательской экспедииии на НЭС «Михаил Сомов» ФГБУ «Северное УГМС», являющейся II этапом крупного национального проекта «ТРАНСАРКТИКА-2019». Комплексные экспедииионные исследования экосистем Баренцева моря были выполнены в соответствии со Cтратегией развития Арктической зоны РФ и обеспечения национальной безопасности на период до 2020 года, а также выполнения программы работ на омывающих берега Российской Федерации морях в соответствии с Приказом Росгидромета № 84 от 26 февраля 2019 года о проведении экспедиции во исполнение Распоряжения Правительства РФ от 23 февраля 2019 года № 276. Также работы были проведены при поддержке проекта Норвежского Фонда Исследований № 13149 ЭСКИМО (ESCIMO) и № 288079 МАЛИНОР (MALINOR). Авторы статьи благодарят за помощь в сборе материала сотрудников ИПЭЭ РАН: кандидата биологических наук Ольгу Виленовну Шпак, Светлану Михайловну Артемьеву, Алексея Александровича Тимшина, и сотрудников ФГБУ Северное «УГМС»-кандидата биологических наук Игоря Юрьевича Попова, Юлию Андреевну Давылову и Чукмасова Павла Викторовича.

International Conference on Marine Geology. - Moscow, Russia, 2019. - P. 326-330.

9. The Arctic Ocean as a dead end for floating plastics in the North Atlantic branch of the Thermohaline Circulation / A. Cózar, E. Martí, C.M. Duarte, J. García-de-Lomas, E. van Sebille, T.J. Ballatore, V.M. Eguíluz, J. Ignacio González-Gordillo, M.L. Pedrotti, F. Echevarría, R. Troublè, X. Irigoien // Science Advances. - 2017. - V. 3. - № 4. - P. 1-8.

10. Global warming releases microplastic legacy frozen in Arctic Sea ice / R.W. Obbard, S. Sadri, Y.Q. Wong, A.A. Khitun, I. Baker, R.C. Thompson // Earth's Future. American Geophysical Union (AGU). - 2014. - V. 2. - № 6. - P. 315-320.

11. González-Fernández D., Hanke G. Toward a harmonized approach for monitoring of riverine floating macro litter inputs to the marine environment // Frontiers in Marine Science. - 2017. - V. 4. - P. 1-7.

12. ФГБУ «ААНИИ» // Арктический и антарктический научноисследовательский институт. 2019. URL: http://www.aari.ru (дата обращения 18.07.2019).

13. First observations on the abundance and composition of floating debris in the North-western Black Sea / G. Suaria, M.C. MelinteDobrinescu, G. Ion, S. Aliani // Marine Environmental Research. 2015. - V. 107. - P. 45-49.

14. National pilot monitoring studies and joint open sea surveys in Georgia, Russian Federation and Ukraine, Final Scientific Report / J. Slobodník, B. Alexandrov, V. Komorin, A. Mikaelyan, A. Guchmanidze, M. Arabidze, A. Korshenko, S. Moncheva. 2017. - № February 2017. - 479 p.

15. Marine litter in the Black Sea region: a review of the problem. Istanbul: Black Sea Commission Publications, 2007. - $160 \mathrm{p}$.

16. Suaria G., Aliani S. Floating debris in the Mediterranean Sea // Marine Pollution Bulletin. - 2014. - V. 86. - P. 494-504.

17. Abundance and composition of floating marine macro litter on the eastern sector of the Mediterranean Sea / E. Constantino, 
I. Martins, J.M. Salazar Sierra, F. Bessa // Marine Pollution Bulletin. - 2019. - V. 138. - № January 2019. - P. 260-265.

18. Herr H. Vorkommen von Schweinswalen (Phocoena phocoena) in Nord- und Ostsee - im Konflikt mit Schifffahrt und Fischerei? Thesis. - Hamburg, 2009. - 120 p.

19. Spatio-temporal distribution of floating objects in the German Bight (North Sea) / M. Thiel, I.A. Hinojosa, T. Joschko, L. Gutow // Journal of Sea Research. - 2011. - V. 65. - № 3. - P. 368-379.

20. Hinojosa I.A., Thiel M. Floating marine debris in fjords, gulfs and channels of southern Chile // Marine Pollution Bulletin. - 2009. V. 58. - № 3. - P. 341-350.

21. The abundance, composition and sources of marine debris in coastal seawaters or beaches around the northern South China Sea (China) / P. Zhou, C. Huang, H. Fang, W. Cai, D. Li, X. Li, H. Yu // Marine Pollution Bulletin. - 2011. - V. 62. - № 9. P. 1998-2007.

22. Titmus A.J., David Hyrenbach K. Habitat associations of floating debris and marine birds in the North East Pacific Ocean at coarse and meso spatial scales // Marine Pollution Bulletin. - 2011. V. 62. - № 11. - P. 2496-2506.

23. Ryan P.G. A simple technique for counting marine debris at sea reveals steep litter gradients between the Straits of Malacca and the Bay of Bengal // Marine Pollution Bulletin. - 2013. - V. 69. № 1-2. - P. 128-136.

24. Ryan P.G., Musker S., Rink A. Low densities of drifting litter in the African sector of the Southern Ocean // Marine Pollution Bulletin. - 2014. - V. 89. - № 1-2. - P. 16-19.
25. Williams R., Ashe E., O'Hara P.D. Marine mammals and debris in coastal waters of British Columbia, Canada // Marine Pollution Bulletin. - 2011. - V. 62. - № 6. - P. 1303-1316.

26. Matsumura S., Nasu K. Distribution of floating debris in the North Pacific Ocean: sighting surveys 1986-1991. - NY: Springer, 1997. - P. 15-24.

27. Titmus A.J., Hyrenbach D.K. Habitat associations of floating debris and marine birds in the North East Pacific Ocean at coarse and meso spatial scales // Marine Pollution Bulletin. - 2011. V. 62. - № 11. - P. 2496-2506.

28. Moore C.J., Moore S.L., Leecaster M.K., Weisberg S.B. A comparison of plastic and plankton in the North Pacific Central Gyre // Marine Pollution Bulletin. - 2001. - № 42 (12). - P. 1297-1300.

29. Ivanova L., Sokolov K., Kharitonova G. Plastic pollution tendencies of the Barents Sea and adjacent waters under the climate change // Arctic and North. - 2018. - V. 32. - № 32. P. 121-145.

30. Международная конвенция по предотвращению загрязнения с судов 1973 г. United Nations, 1997. - 26 c.

31. Black sea marine litter regional action plan. - Istanbul, Black Sea Commission Publications, 2018. $-30 \mathrm{p}$.

Поступила 13.01.2021 2.

\section{Информация об авторах}

Погожсва М.П., аспирант Института океанологии им. П.П. Ширшова Российской академии наук; старший научный сотрудник Государственного океанографического института им. Н.Н. Зубова, Росгидромет.

Якушев E.B., доктор физико-математических наук, главный научный сотрудник Института океанологии им. П.П. Ширшова Российской академии наук; старший научный сотрудник, Норвежский институт водных исследований.

Терский П.Н., младший научный сотрудник Государственного океанографического института им. Н.Н. Зубова. Глазов Д.М., ведущий инженер Института проблем экологии и эволюции им. А.Н. Северцова Российской академии наук.

Аляутдинов В.А., научный сотрудник Государственного океанографического института им. Н.Н. Зубова.

Коршенко A.H., кандидат биологических наук, заведующий отделом мониторинга морской среды Государственного океанографического института им. Н.Н. Зубова, Росгидромет.

$\boldsymbol{X а н к е ~} \boldsymbol{\Gamma}$., доктор философии по химии $(\mathrm{PhD})$, старший научный сотрудник Объединенного научного центра.

Семилетов И.П., член-корреспондент РАН, доктор географических наук, заведующий лабораторией арктических исследований Тихоокеанского океанологического института им. В.И. Ильичева Дальневосточного отделения Российской академии наук. 
UDC 504.42(269.718):504.054

\section{ASSESSMENT OF BARENTS SEA FLOATING MARINE MACRO LITTER POLLUTION DURING THE VESSEL SURVEY IN 2019}

Maria P. Pogojeva1,2, pogojeva_maria@mail.ru

Evgeniy V. Yakushev1,3, evgeniy.yakushev@niva.no

Petr N. Terskiy², peter.tersky@gmail.com

Dmitry M. Glazov4, dglazov@yandex.ru

\author{
Vadim A. Alyautdinov², \\ vada.90@mail.ru
}

\begin{abstract}
Alexander N. Korshenko²,
\end{abstract} korshenk058@mail.ru

Georg Hanke ${ }^{5}$,

georg.hanke@ec.europa.eu

\section{Igor P. Semiletov 6 ,}

igorsm@poi.dvo.ru

1 Shirshov Institute of Oceanology of Russian Academy of Sciences,

36, Nakhimovskiy avenue, Moscow, 117997, Russia.

2 N.N. Zubov State Oceanographic Institute, Roshydromet,

6, Kropotkinskiy lane, Moscow, 119034, Russia.

3 Norwegian Institute of Water Research, Gaustadalleen 21, Oslo, 0345, Norway.

${ }^{4}$ A.N. Severtsov Institute of Ecology and Evolution of Russian Academy of Sciences, 33, Leninsky avenue, Moscow, 119071, Russia.

5 European Commission Joint Research Centre, Via Enrico Fermi 2749, I-21027 Ispra (VA).

6 V.I. Ilyichov Pacific Oceanological Institute, Far Eastern Branch of the Russian Academy of Sciences, 43, Baltic street, Vladivostok, 690041, Russia.

The relevance of the research is caused by the increasing accumulation of plastic debris in the marine environment, which has raised serious concerns in the scientific community as well as in the general public. Increasing litter concentrations have a growing impact on living organisms, the quality of marine waters and the ecosystem as a whole, often affecting living and health conditions of human beings as well. Taking into account the global water masses circulation, environmental conditions and constantly increasing anthropogenic pressure related to the global warming, the Arctic could potentially serve as a place for the permanent accumulation of plastic waste. Furthermore, the Arctic ecosystem, considered as pristine and fragile environment, could particularly suffer from increasing litter occurrence. The main objectives of this work were the acquisition of new data on the potential accumulation areas of floating marine macro litter (FMML) in the Barents Sea, an initial assessment of the level of pollution by FMML in the Arctic and an analysis of potential sources.

Methods. During the survey new methods for FMML monitoring were tested and combined with visual observations, a mobile application was used in order to simplify the harmonized collection of data.

The results of this study present the first data on pollution of the eastern part of the Barents Sea by FMML. It was found that the average density corresponds to 3,5 items $/ \mathrm{km}^{2}$. At some transects along the vessel route, numerous significant areas of accumulation of FMML were noted, which was not reported before in the scientific literature. Some practical recommendations were made in the conclusions to reduce the amount of litter entering the marine environment, and the need of regular monitoring studies was highlighted.

\section{Key words:}

Marine pollution, marine floating macro litter, Arctic, Barents Sea, marine environmental monitoring.

The studies were organized within the framework of a comprehensive research expedition of the FSBI «Northern Directorate for Hydrometeorology and Environmental Monitoring» on the $R / V$ Mikhail Somov, which was the II stage of the national project TRANSARCTICA-2019. The field studies of the ecosystems of the Barents Sea were carried out in accordance with the Strategy for the Development of the Arctic Zone of the Russian Federation and Ensuring National Security for the period up to 2020, as well as the implementation of the work program on the Russian seas in accordance with the Order of Roshydromet No. 84 dated February 26, 2019 on conducting an expedition in pursuance of the Order of the Government of the Russian Federation of February 23, 2019 No. 276. The work was also carried out with the support of the Norwegian Research Foundation project No. 13149 ESCIMO and No. 288079 MALINOR. The authors of the article thank the staff of the A.N. Severtsov Institute of Ecology and Evolution RAS Olga Shpak, Svetlana Artemieva, Aleksey Timshin and the staff of FSBI «Northern Directorate for Hydrometeorology and Environmental Monitoring» Igor Popov, Yulia Davydova and Pavel Chukmasov for their help in collecting the field data.

\section{REFERENCES}

1. Kershaw P.J. Marine plastic debris and microplastics global lessons and research to inspire action and guide policy change. Nairobi, UNEP, 2016. 192 p.
2. Jambeck J.R., Geyer R., Wilcox C., Siegler T.R., Perryman M., Andrady A., Narayan R., Law K.L. Plastic waste inputs from land into the ocean. Science. American Association for the Advancement of Science, 2015, vol. 347, no. 6223, pp. 768-771. 
3. Galgani F., Hanke G., Werner S., Oosterbaan L., Nilsson P., Fleet D., Kinsey S., Van Franeker J., Vlachogianni T., Scoullos M., Mira Veiga J., Palatinus A., Matiddi M., Maes T., Korpinen S., Budziak A., Leslie H., Gago J., Liebez G. Guidance on monitoring of marine litter in European Seas. European Commission, Joint Research Centre. MSFD Technical Subgroup on Marine Litter (TG ML), 2013, no. EUR 26113, pp. 1-126.

4. Ross N.L. The «plasticene» epoch? Elements. Mineralogical Society of America, 2018, vol. 14, no. 5, pp. 291-292.

5. Van Sebille E., England M.H., Froyland G. Origin, dynamics and evolution of ocean garbage patches from observed surface drifters, Environmental Research Letters. Institute of Physics Publishing, 2012, vol. 7, no. 4, pp. 1-6.

6. Kuhlbrodt T., Griesel A., Montoya M., Levermann A., Hofmann M., Rahmstorf S. On the driving processes of the Atlantic meridional overturning circulation. Reviews of Geophysics, 2007 vol. 45, no. 2, pp. 2001-2002.

7. Rudels B. Arctic ocean circulation. Encyclopedia of Ocean Sciences, 2019, pp. 262-277.

8. Yakushev E., Pakhomova S., Lusher A.L., Mazur A., Grinko A., Dautova T., Kosmach D., Berezina A. Studies of microplastic distribution in subsurface waters of the Arctic Seas in the 73 cruise of RV «Akademik Mstislav Keldysh», September-October 2018. Geology of seas and oceans: Proc. of XXIII International Conference on Marine Geology. Moscow, Russia, 2019. pp. 326-330.

9. Cózar A., Martí E., Duarte C.M., García-de-Lomas J., Van Sebille E., Ballatore T.J., Eguíluz V.M., Ignacio González-Gordillo J., Pedrotti M.L., Echevarría F., Troublè R., Irigoien X. The Arctic Ocean as a dead end for floating plastics in the North Atlantic branch of the Thermohaline Circulation. Science Advances, 2017, vol. 3, no. 4, pp. 1-8.

10. Obbard R.W., Sadri S., Wong Y.Q., Khitun A.A., Baker I., Thompson R.C. Global warming releases microplastic legacy frozen in Arctic Sea ice. Earth's Future. American Geophysical Union (AGU), 2014, vol. 2, no. 6, pp. 315-320.

11. González-Fernández D., Hanke G. Toward a harmonized approach for monitoring of riverine floating macro litter inputs to the marine environment. Frontiers in Marine Science, 2017, vol. 4, pp. 1-7.

12. State Research Center "Arctic and Antarctic Research Institute» (AARII), 2019. Availble at: http://www.aari.ru (assessed 18 July 2019).

13. Suaria G., Melinte-Dobrinescu M.C., Ion G., Aliani S. First observations on the abundance and composition of floating debris in the North-western Black Sea. Marine Environmental Research, 2015, vol. 107 , pp. 45-49.

14. Slobodník J., Alexandrov B., Komorin V., Mikaelyan A., Guchmanidze A., Arabidze M., Korshenko A., Moncheva S. National pilot monitoring studies and joint open sea surveys in Georgia, Russian Federation and Ukraine. Final Scientific Report, 2017, February, $479 \mathrm{p}$.

15. Marine litter in the Black Sea Region: A review of the problem. Istanbul, Black Sea Commission Publications, 2007. 160 p.
16. Suaria G., Aliani S. Floating debris in the Mediterranean Sea. Marine Pollution Bulletin, 2014, vol. 86, pp. 494-504.

17. Constantino E., Martins I., Salazar Sierra J.M., Bessa F. Abundance and composition of floating marine macro litter on the eastern sector of the Mediterranean Sea. Marine Pollution Bulletin, 2019, vol. 138, no. January 2019, pp. 260-265.

18. Herr H. Vorkommen von Schweinswalen (Phocoena phocoena) in Nord- und Ostsee - im Konflikt mit Schifffahrt und Fischerei? Thesis. Hamburg, 2009. $120 \mathrm{p}$

19. Thiel M., Hinojosa I.A., Joschko T., Gutow L. Spatio-temporal distribution of floating objects in the German Bight (North Sea). Journal of Sea Research. Elsevier, 2011, vol. 65, no. 3, pp. 368-379.

20. Hinojosa I.A., Thiel M. Floating marine debris in fjords, gulfs and channels of southern Chile. Marine Pollution Bulletin, 2009, vol. 58, no. 3, pp. 341-350.

21. Zhou P., Huang C., Fang H., Cai W., Li D., Li X., Yu H. The abundance, composition and sources of marine debris in coastal seawaters or beaches around the northern South China Sea (China) Marine Pollution Bulletin, 2011, vol. 62, no. 9, pp. 1998-2007.

22. Titmus A.J., Hyrenbach D.K. Habitat associations of floating debris and marine birds in the North East Pacific Ocean at coarse and meso spatial scales. Marine Pollution Bulletin, 2011, vol. 62, no. 11 , pp. $2496-2506$.

23. Ryan P.G. A simple technique for counting marine debris at sea reveals steep litter gradients between the Straits of Malacca and the Bay of Bengal. Marine Pollution Bulletin, 2013, vol. 69, no. 1-2, pp. 128-136.

24. Ryan P.G., Musker S., Rink A. Low densities of drifting litter in the African sector of the Southern Ocean. Marine Pollution Bulletin, 2014, vol. 89, no. 1-2, pp. 16-19.

25. Williams R., Ashe E., O'Hara P.D. Marine mammals and debris in coastal waters of British Columbia, Canada. Marine Pollution Bulletin, 2011, vol. 62, no. 6, pp. 1303-1316.

26. Matsumura S., Nasu K. Distribution of floating debris in the North Pacific Ocean: sighting surveys 1986-1991. NY, Springer, 1997. pp. 15-24.

27. Titmus A.J., David Hyrenbach K. Habitat associations of floating debris and marine birds in the North East Pacific Ocean at coarse and meso spatial scales. Marine Pollution Bulletin, 2011, vol. 62, no. 11, pp. 2496-2506.

28. Moore C. J., Moore S. L., Leecaster M. K., Weisberg S.B. A comparison of plastic and plankton in the North Pacific Central Gyre. Marine Pollution Bulletin, 2001, no. 42 (12), pp. 1297-1300.

29. Ivanova L., Sokolov K., Kharitonova G. Plastic pollution tendencies of the Barents Sea and adjacent waters under the climate change. Arctic and North, 2018, vol. 32, no. 32, pp. 121-145.

30. Mezhdunarodnaya konvenciya po predotvrashcheniyu zagryazneniya s sudov 1973 [International Convention for Prevention of Pollution from Ships 1973]. United Nations, 1997. 26 p.

31. Black Sea Marine Litter Regional Action Plan. Istanbul, Black Sea Commission Publications, 2018. 30 p.

Received: 13 January 2021.

\section{Information about the authors}

Maria P. Pogojeva, postgraduate student, Shirshov Institute of Oceanology of Russian Academy of Sciences; senior scientist, N.N. Zubov State Oceanographic Institute, Roshydromet.

Evgeniy V. Yakushev, Dr. Sc., leading scientist, Shirshov Institute of Oceanology of Russian Academy of Sciences; senior research scientist, Norwegian Institute of Water Research.

Petr N. Terskiy, junior scientist, N.N. Zubov State Oceanographic Institute, Roshydromet.

Dmitry M. Glazov, principal engineer, A.N. Severtsov Institute of Ecology and Evolution of Russian Academy of Sciences.

Vadim A. Alyautdinov, research scientist, N.N. Zubov State Oceanographic Institute, Roshydromet.

Alexander N. Korshenko, Cand. Sc., Head of the Marine Monitoring Department, N.N. Zubov State Oceanographic Institute, Roshydromet.

Georg Hanke, PhD, senior scientist, EC Joint Research Centre.

Igor P. Semiletov, Dr. Sc., Head of the Laboratory of Arctic Research, V.I. Ilyichov Pacific Oceanological Institute, Far Eastern Branch of the Russian Academy of Sciences. 